2. Hotez PJ, Brooker S, Bethony JM, Bottazzi ME, Loukas A, Xiao S. Hookworm Infection. N Engl J Med 2004; 351: 799-807.

3. Cabezas MT, Jiménez MJ, Molina MA, Cruz G, Avivar C, Ortiz B. Anemia ferropénica y síndrome constitucional. Enferm Infecc Microbiol Clin 200; 18: 239-240.

4. Roca C, Balanzó X, Sauca G, Fernández-Roure JL, Boixeda R, Ballester M. Uncinariasis importada por inmigrantes africanos: estudio de 285 casos. Med Clin (Barc) 2003; 121: 139-41.

5. Turrientes López MC, López-Vélez R. Diagnóstico de parasitosis intestinales. Jano 2003; 1458: 39-2.

6. Valerio L, Sabriá M, Fabregat A. Las enfermedades tropicales en el mundo occidental. Med Clin (Barc) 2002; 118: 508-14.

7. Aparicio P, Rodríguez E, Gárate T, Molina R, Soto A, Alvar J. Terapéutica antiparasitaria. Enferm Infecc Microbiol Clin 2003; 21: 579-94.

8. Turrientes MC, Huerga H, López-Vélez R. Coste económico y carga asistencial en el laboratorio de parasitología derivados de la atención al inmigrante. Enferm Infecc Microbiol Clin 2003; 21: 188-92

9. Martín Sánchez AM, Hernández García A, González Fernández M, Alfonso Rodríguez O, Hernández Cabrera M, Pérez Arellano JL. Parasitosis intestinales en población inmigrante subsahariana asintomática. Gran Canaria 2000. Rev Clin Esp 2004; 204:

\section{Sepsis de repetición en un paciente con gammapatía monoclonal de significado incierto}

\section{Sr. Director:}

La gammapatía monoclonal de significado incierto (GMSI) es un trastorno de las células plasmáticas consistente en la proliferación monoclonal de células plasmáticas y producción de un pico monoclonal de inmunoglobulinas. Estas entidades se acompañan de una alteración en el sistema inmunitario, principalmente inmunosupresión humoral, lo cual supone una mayor predisposición para procesos infecciosos (1-3). Describiremos el curso clínico de un paciente con GMSI cuya principal manifestación clínica es la presencia de procesos infecciones de repetición que cedieron tras la instauración de tratamiento citostático.

Paciente de 46 años de edad, sin antecedentes personales de interés, que acude al Servicio de Urgencias por dolor y distensión abdominal de cuatro días de evolución. Dos días antes había presentado fiebre y escalofríos. En la exploración destacaba una adenopatía supraclavicular izquierda, desnutrición moderada y abdomen globuloso, depresible, doloroso de forma difusa, sin masas ni megalias palpables. En las pruebas complementarias destacaba: leucocitos $13.500 / \mathrm{mm} 3$ (82\% neutrófilos), proteínas totales 7,8 g/dl, LDH $569 \mathrm{U} / \mathrm{l}$, Ig G $1170 \mathrm{ml} / \mathrm{dl}$, Ig A $197 \mathrm{mg} / \mathrm{dl}$, Ig M 2940 mg/dl, cadenas ligeras Kappa 248 $\mathrm{mg} / \mathrm{dl}(\mathrm{N}<370)$, cadenas ligeras Lambda $62 \mathrm{mg} / \mathrm{dl}(\mathrm{N}<210)$, cociente K/L 4. Crioglobulinas positivas. En la tomografía axial computerizada (TAC) se observó derrame pleural bilateral, 2 lesiones nodulares hepáticas, esplenomegalia homogénea, adenopatías en hilio esplénico, raíz de mesenterio y retroperitoneo $<1,5 \mathrm{~cm}$ y moderada ascitis. En la citología del líquido pleural se observó Linfocitos CD 45+ sugestivo de linfoma. La biopsia ganglionar y de médula ósea (BMO) mostró cambios reactivos. Se realizó laparotomía exploradora y el informe anatomopatológico de las muestras ganglionares y tejido hepático mostró linfadenitis y cambios reactivos inespecíficos. Durante el ingreso presenta dos episodios de sepsis sin foco claro que respondió a antibioterapia de amplio espectro. En los siguientes dos años el paciente ingresó en seis ocasiones por episodios de sepsis con criterios de gravedad. Solo en una ocasión los hemocultivos fueron positivos para Salmonella enteritidis, Escherichia coli y Klebsiella pneumoniae. Durante el tiempo de seguimiento, per- sistió la gammapatia monoclonal a expensas de Ig M, con cifras máximas de $2.949 \mathrm{mg} / \mathrm{dl}$, y los mismos hallazgos en los TAC de control. Se realizó esplenectomía que también mostró cambios reactivos inespecíficos. A los 32 meses del inicio de los síntomas ingresa por nuevo episodio febril. En el TAC se aprecian adenopatías retroperitoneales de $6 \times 4 \mathrm{~cm}$, se realiza PAAF que fue positiva para células linfoplasmocitarias. Con estos datos se establece el diagnóstico de linfoma linfoplasmocitario y se inicia quimioterapia con esquema Mabthera, ciclofosfamida, vincristina y prednisona (CVP), de los que recibió 8 ciclos con respuesta completa y sin nuevos episodios de sepsis.

La gammapatía monoclonal de significado incierto (GMSI) es una entidad caracterizada por la presencia de un pico monoclonal de inmunoglobulinas en pacientes sin evidencia de mieloma múltiple, macroglobulinemia de Waldestrom, amiloidosis primaria o cualquier enfermedad linfoproliferativa $(1,2,4)$ y suele ser un hallazgo casual de laboratorio. El riesgo de progresión tumoral se establece en torno al $1 \%$ por año $(2,5,6)$, sobre todo hacia mieloma múltiple y síndromes linfoproliferativos. En la literatura son escasas las referencias que relacionan la GMSI con la recurrencia de procesos infecciosos, aunque existen algunos artículos que nos hablan de un incremento del riesgo de bacteriemia en los pacientes con GMSI. En 1994 Chapel y Lee (7) observaron, en una serie de 19 pacientes con GMSI, un riesgo medio estimado de padecer procesos infecciosos con criterios de gravedad en 0,2 paciente/año. Este estudio es descriptivo, con un escaso tamaño muestral y sin una población control. Gregersen y cols. (8) analizaron 1237 pacientes con GMSI con un seguimiento de 13 años y describieron 40 episodios de bacteriemia, cuyos gérmenes más frecuentes fueron Enterobacterias, Staphylococcus aureus, Pneumococo, Enterococus y Bacteroides species. El riesgo estimado de bacteriemia fue de 2,2 (CI 95\% 1,63,0 ), aunque no mostró significación estadística, y la mediana de tiempo desde el diagnóstico hasta el primer episodio de bacteriemia fue de 735 días, con un rango de 35-3.236 días.

Aunque existen pocos datos sobre el riesgo de infección en las GMSI y no se ha podido encontrar una verdadera asociación entre ambos, nuestro caso y los resultados encontrados por otros autores, indican que los pacientes con una GMSI pudieran presentar un mayor riesgo de sepsis y bacteriemias. Habría que establecer si las sepsis de repetición en un paciente con GSMI fuese una indicación de tratamiento específico, aunque no exista transformación neoplásica.

\section{R. D. García Marrero, M. M. Alonso Socas, J. Oramas Rodrí- guez, B. Alonso Álvarez, N. Batista López}

Servicios de Oncología Médica y Medicina Interna. Hospital Universitario de Canarias. La Cuesta. La Laguna, Tenerife

1. Kyle RA. Monoclonal gammopathy of undetermined significance. Natural history in 241 cases. Am J Med 1978; 64: 814.

2. Kyle RA, Rajkumar SV. Monoclonal gammopathies of undetermined significance: a review. Immunol Rev 2003; 194: 112-139.

3. Axelsson U, et al. Frequency of pathological proteins (M-components) in 6,995 sara from an adult population. Acta Med Scan 1966: 179: 235-247.

4. Saleum JP, et al. Monoclonal gammopathies in the adult population of Finistere, France. J Clin Pathol 1982; 35: 63-68.

5. Kyle RA, et al. A long-term study of prognosis in monoclonal gammopathy of undetermined significance. N Engl J Med 2002; 346: 564-569.

6. Cesana $\mathrm{C}$, et al. Prognostic factors for malignant transformation in monoclonal gammopathy of undetermined significance and smouldering multiple myeloma. J Clin Oncol 2002; 20: 1625-1634.

7. Chapel HM, Lee M. The use of intravenous immune globulin in multiple myeloma. Clin Exp Immunol 1994: 97 (Supl. 1): 21-24.

8. Gregersen H, Madsen KM, Sorensen HT, Schonheyder HC, Ibsen JS, Dahlerup JF. The risk of bacteremia in patients with monoclonal gammopathy of undetermined significance. Eur J Haematol 1998; 61: 140-144. 